\title{
ENVIRONMENT AND SELECTION IN DROSOPHILA MELANOGASTER
}

\author{
M. J. LAWRENCE \\ Department of Genetics, The University, Birmingham, 15
}

1. INTRODUCTION

Received I5.ix.63

IT is a common experience in selection programmes to find that while considerable progress can be obtained during the early generations of selection, sooner or later, the response to selection becomes negligible (Mather, I94I; Mather and Harrison, I949; Robertson, I955; Rasmuson, 1955; Clayton and Robertson, 1957). Any selection line will reach, of course, a limit when all relevant loci have become homozygous, whether or not they become homozygous with respect to those alleles favoured by selection. But, as has been shown several times, not all limits to selection are of this kind, since later progress has been obtained by persisting with or by reversing the direction of or merely by relaxing selection for a few generations.

It is convenient to refer to the first type of limit as a ceiling and to the second type as a plateau. Mutation apart, a ceiling is static and final whereas a plateau, being transitory, must have a dynamic quality.

Now there appears to be no generally accepted theory concerning the causation of plateaus in selection experiments, there being as many views as authors who have considered this problem. One, favoured by Lerner (1958), supposes that genetic variability for the trait in question does in fact exist in the selection line, but that it is not expressed in the environment in which selection is being practised. Glearly, the implication here is that an appropriate change of environment ought to result in further advances under selection.

Another view, proposed by Mather and Harrison (1949), also supposes that genetic variability is to be found in the line, but that it is not available to selection because of disadvantageous linkages between genes determining the trait in question and those determining fitness. This interpretation assumes that the chromosomes carry both genetic systems, an assumption whose validity has been confirmed by Breese and Mather (1957, 1960) with respect to chaeta number and viability in Drosophila melanogaster at least. A plateau, then, is to be expected whenever chromosomes carrying alleles favoured by experimental selection carry also those determining low fitness. Hence these chromosomes are at a selective disadvantage from the point of view of natural selection and an equilibrium maintained by the opposing forces of natural and experimental selection results. Such an equilibrium can be disturbed only by breaking the disadvantageous linkages between those genes determining the favoured trait and those determining low fitness. 
It is not easy to design experiments to distinguish between these two views, nor is it easy to decide what type of evidence should unambiguously favour one view rather than the other. For instance, where the effect of persistent and prolonged selection in a constant environment is to disrupt a plateau, this might be held to favour the correlated response view. But need the environment be the only agency capable of modifying the expression of genes? The effect of continuous selection on the genetic background could well enhance the expressivity of determinative genes to the point where they eventually become available for selection. On the other hand, the disruption of a plateau by changing the environment favours both views, since, as is well known, the frequency of recombination between genes is sensitive to certain environmental variation (Plough, I9I7). For convenience, the results of the experiment to be described later, will be interpreted from the correlated response point of view, rather than that concerned with expressivity, for reasons discussed later.

Now the disruption of the equilibrium envisaged by the correlated response theory depends on the breakage of the repulsion linkages between those genes of primary concern and those determining low fitness. In principle, there are two ways of doing this, for the probability of recovering a recombinant genotype is a function of two variables; the size of progeny from which the parents of the next generation are selected and the average frequency of recombination between the genes in question. Of these two variables, the potentialities of the first appear to have been exploited more often. Thus it is clear that, at equilibrium, the size of family cannot be increased while selection is continued because of the low average fitness of the individual members of that family. Selection is therefore relaxed until such time that the average fitness of the line, and hence the size of family has increased to the point where the resumption of selection is practicable. This approach has proved quite successful (see Mather and Harrison (1949) and Rasmuson ( 1955 ) for example), even though it results in a temporary loss in the value of the character for which selection has been practiced. This loss, however, is more than made good when selection is resumed.

The exploitation of the second variable, on the other hand, has received less attention, although Rasmuson (1955) explored the effect of temperature shocks on progress under selection with little apparent effect. The experiment to be described here was designed to provide some information concerning the effect of more prolonged temperatures on the progress of selection, since, as mentioned earlier, it is well known that this environmental variable can change the frequency of recombination.

Selection for high and for low sternopleural chaeta number was therefore begun among the progeny of a cross between the two inbred lines of Drosophila melanogaster, Oregon and Samarkand. Selection was practised in each of two environments provided by incubators set at 
I $8^{\circ} \mathrm{G}$. and $25^{\circ} \mathrm{G}$. In each environment, selection was continued until each line, high and low, reached a plateau in response to selection. When this had happened, a sub-line was set-up from each main selection line and transferred to the alternative environment, selection being continued in both lines and in both environments. In this way it was hoped to investigate the effect of change of environment on the disruption of plateaus in selection experiments.

\section{MATERIALS AND METHODS}

All selection lines were duplicated by adopting the cyclical method of mating in maintaining the lines. In each generation, twenty virgin males and twenty virgin females were scored in each pair of replicates. From among these, the two females with the most extreme number of bristles were mated with the two most extreme males from the sister replicate in a positive assortative fashion. At the same time, the next most extreme males and females were used as parents in case the most extreme matings failed, which they occasionally did. With the exception of such failures, Io per cent. of the progeny scored in any one generation were selected as parents of the next.

All matings were carried out in the usual $3 \times \mathrm{I}$ inch glass tubes, where flies were held for two days at $25^{\circ} \mathrm{C}$. and for four days at $18^{\circ} \mathrm{C}$. before being transferred to the customary half-pint milk bottles. All other technical details were those usual for experiments with Drosophila.

\section{RESULTS}

(a) The main selection lines

These are those lines which were maintained in the same environment throughout their histories. Those lines whose environment was

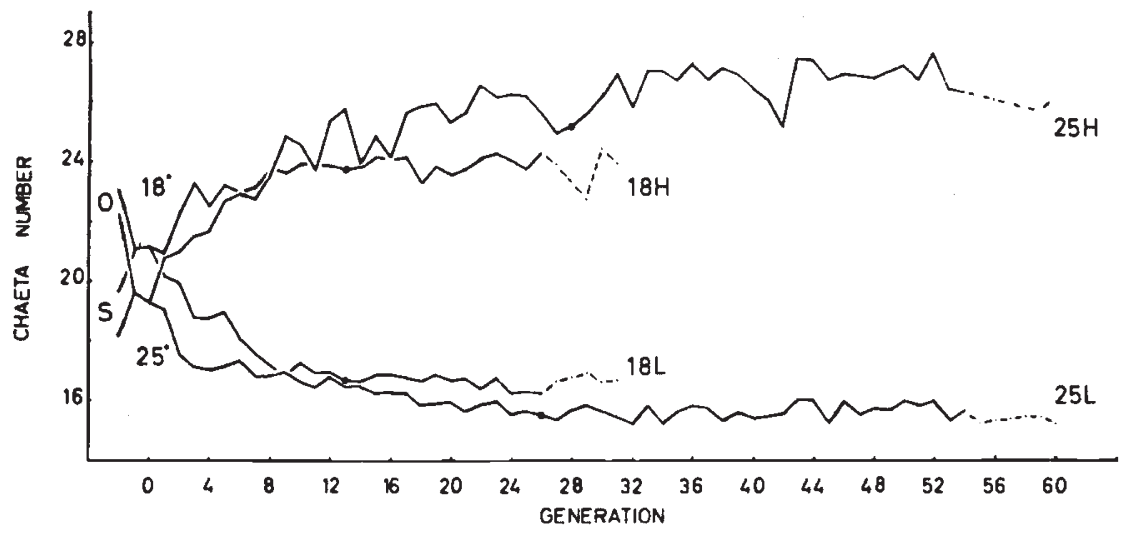

Fig. 1. Response to selection for sternopleural chaeta number in the main lines. Broken lines indicate where selection was discontinued. The dots show the generations at which the sub-lines were established. $\mathrm{O}=$ Oregon; $\mathrm{S}=$ Samarkand. Points are averages of male and female counts in every generation.

changed during the course of selection are referred to as the sub-lines. The progress of selection in the main lines is shown in fig. I. Selection was continued for a total of 54 generations at $25^{\circ} \mathrm{C}$., but only 26 generations at $18^{\circ} \mathrm{C}$., the difference being due to the extended life-cycle of the flies in the latter environment. 
The environment appears to have influenced response to selection in two ways; in respect of overall response and in respect of the asymmetry of response. After 26 generations of selection, the response obtained at $25^{\circ} \mathrm{C}$. is apparently greater than that obtained after the same number of generations at $18^{\circ} \mathrm{C}$. On the other hand the asymmetry of response at $18^{\circ} \mathrm{C}$. is slightly greater in magnitude and opposite in direction to that observed at $25^{\circ} \mathrm{C}$. But these comparisons must be treated with caution, for examination of the parent lines shows that the temperature of the environment has, as is well known (Plunkett, 1926; Gibson, Parsons and Spickett, I961), a direct effect on the expression of chaeta number. The mid-parent value at $18^{\circ} \mathrm{C}$. exceeds that at $25^{\circ} \mathrm{C}$. by $\mathrm{I} \cdot \mathrm{I}$ chaetæ, so that a valid assessment of the effect of the environment on response to selection can only be made on the basis of comparisons within environments.

The first generations of the sub-lines allow such comparisons and, to anticipate later discussion, it is at once clear that the total response obtained at $25^{\circ} \mathrm{C}$. (after 26 generations of selection) is only fractionally greater than that obtained at $18^{\circ} \mathrm{C}$. Furthermore, asymmetry turns out to be purely a function of the environment for its direction at $18^{\circ} \mathrm{C}$. with respect to the main lines of this environment is reversed when these are raised at $25^{\circ} \mathrm{C}$. The converse is also true with respect to the asymmetry of the $25^{\circ} \mathrm{C}$. main lines when these are raised at $18^{\circ} \mathrm{C}$.

The response obtained under selection must, of course, depend on the amount of genetic variation available and in the present case this initially was the same in both environments, since in both, the "base" population was the $F_{2}$ of a cross between Oregon and Samarkand. Furthermore, since the overall responses obtained at $18^{\circ} \mathrm{C}$. and $25^{\circ} \mathrm{C}$. are similar, this must be taken to imply that the amounts of genetic variation available to selection throughout the course of the experiment were also similar. Yet among the agencies determining the availability of variation, that of recombination is known to vary with the temperature of the environment (Plough, 1917), particularly in the case of the $\mathrm{X}$ chromosomes of the inbred lines used as parents here (Lawrence, 1958, 1963). Since the average frequency of recombination between certain loci at least has been shown to be higher at $18^{\circ} \mathrm{C}$. than at $25^{\circ} \mathrm{C}$., it follows that we expect to observe a greater response to selection in the former environment than in the latter. It is therefore clear that the situation envisaged here is over simple and we must turn to consider other effects of the environment on the availability of genetic variation.

Among these, the effect of the environment on the average fitness of the lines is of obvious importance. Now although no gross difference with respect to the fitnesses of the various lines were in fact observed during the course of the experiment, there are good grounds for expecting this to be lower at $18^{\circ} \mathrm{C}$. than at $25^{\circ} \mathrm{C}$., whether or not such a difference would be open to casual observation. The inbred lines 
used to raise the $F_{2}$ populations from which selection was begun have been kept at $25^{\circ} \mathrm{C}$. for many generations. It is therefore reasonable to suppose that the parent lines have become adapted to this temperature. Thus the disappointing response to selection obtained at $18^{\circ} \mathrm{C}$. could imply not that the frequency of recombination is similar in this environment to that at $25^{\circ} \mathrm{C}$., but that the environment determines that a smaller proportion of recombinant genotypes survive to contribute to the next generation. In other words, the environment at $18^{\circ} \mathrm{G}$., by affecting fitness, is limiting the availability of genetic variation even though there are good grounds for expecting the supply of variation, through recombination, to be greater at $18^{\circ} \mathrm{C}$. than at $25^{\circ} \mathrm{C}$. The results obtained from other parts of the experiment are at least consistent with this argument, even though we have no corroborative evidence available at the moment.

\section{(b) The sub-lines}

The main purpose of the experiment was to investigate the effects of a change of environment on the stability of plateaus in response to selection. The intention was therefore to continue selection in the main lines until each had reached a plateau. A sub-line would then be set-up from each main line, selection being continued in this sub-line, but in the alternative environment. The progress, if any, of each sub-line could then be observed using that of its main line, in which selection would also be continued, as a standard.

This procedure was in fact followed, although a difficulty here is the rapid detection of a plateau, which is, of course, more easily seen in retrospect. It is necessary therefore, to adopt, in advance, some kind of criterion to determine where a sub-line should be started. The criterion adopted was to set-up a sub-line as soon as five successive generations of selection in a main line had resulted in no more than a negligible response. This happened after thirteen generations of selection in both lines at $18^{\circ} \mathrm{C}$. ( $18 \mathrm{H}$ and $18 \mathrm{~L}$ ); after twenty-eight generations in the high line at $25^{\circ} \mathrm{C}$. $(25 \mathrm{H})$; and after twenty-six generations of selection in the low line at $25^{\circ} \mathrm{C}$. $(25 \mathrm{~L})$. These forecasts turned out to be reasonably accurate in the case of the $18 \mathrm{H}$ and $25^{\mathrm{L}}$ lines, but premature for the remaining lines, $18 \mathrm{~L}$ and ${ }_{25} \mathrm{H}$. Thus nearly two chaetæ were gained in the $25 \mathrm{H}$ line immediately after the diagnosis of a plateau, although no progress was observed thereafter. The $18 \mathrm{~L}$ line lost half a chaeta rather gradually over the remaining 13 generations of selection, but in neither case was it thought worthwhile setting-up the sub-lines afresh in view of the much greater progress made in both prior to the establishment of their sub-lines.

The progress of selection in the four sub-lines is shown in fig. 2. The immediate effect of a change of environment on chaeta number varies considerably over the lines. The low lines appear to be insensitive to the environment, but in the high lines, the response is both large and significant. The progenies of flies taken from the $18 \mathrm{H}$ 
line when raised at $25^{\circ} \mathrm{C}$. have an average of $\mathrm{I} \cdot 4$ chaetæ more than their sibs held at $18^{\circ} \mathrm{C}$. Correspondingly, the progenies of flies taken from the $25 \mathrm{H}$ line when raised at $18^{\circ} \mathrm{C}$., average 1.7 chaetæ fewer than their sibs at $25^{\circ} \mathrm{C}$. This evidence therefore suggests that the relation between temperature and chaeta number is positive. Yet as we have seen from the behaviour of the parent lines in this experiment, as well as that from a wide range of material reported in the literature, the usual relationship is a negative one. It appears that this reversal of the usual response of chaeta number to change of temperature is a side-effect of selection for increased or decreased number. But before discussing this possibility it is worth pointing out that we ought not to

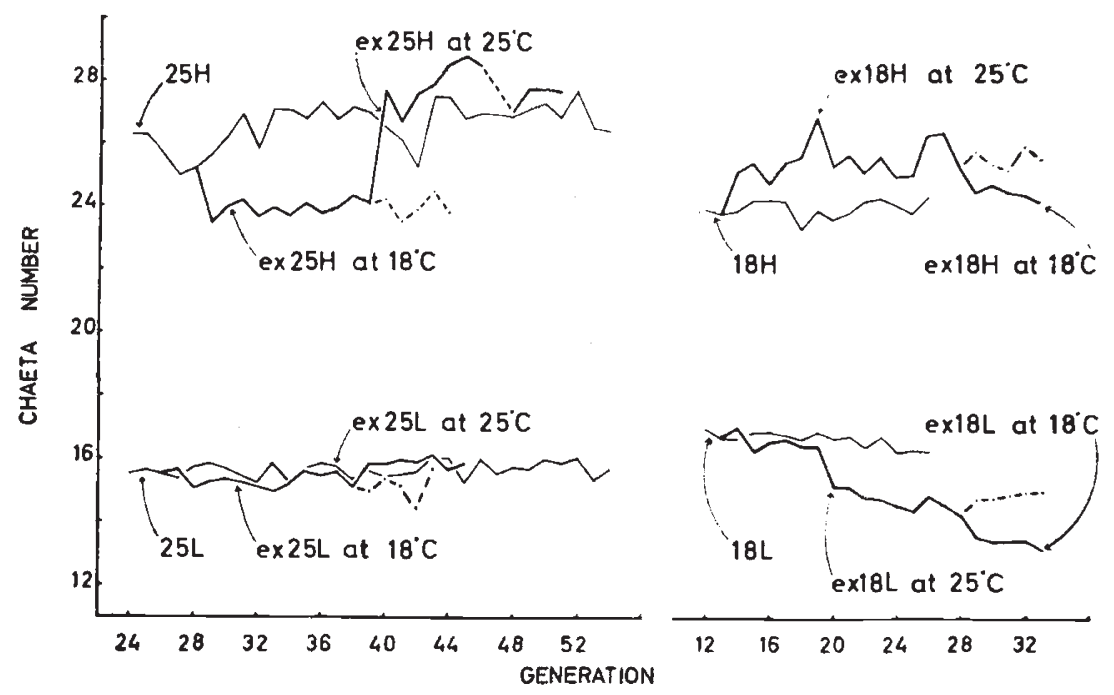

Frg. 2.-Response to selection in the sub-lines. The main lines are also shown, for the purpose of comparison. Other details, as in fig. 1 .

assume that these selection lines were not segregating, for the $2{ }_{5} \mathrm{H}$ line clearly was. Selection may therefore be directly implicated and in any case it is convenient to hold over discussion here until more evidence has been examined.

Turning, therefore, to the longer term progress of the sub-lines, only one, the ex $18 \mathrm{~L}$ line, provides any evidence of progress prior to its return to its home environment. The response obtained in this line, however, is considerable, amounting to a loss of 2.8 chaetæ, most of which ( 1.3 chaetæ) were lost between the sixth and seventh generation of selection in the foreign environment ( $\mathbf{S}_{19}$ and $\mathbf{S}_{20}$ ). A response of this magnitude, except in the initial generations of a selection programme when whole chromosomes are segregating, suggests that a major gene could be concerned and indeed some three generations later ( $\mathbf{S}_{23}$ ), it was noticed that most of the individuals scored displayed a slight wing abnormality. In these, an extra piece of vein appeared to have been inserted between the exterior edge of the wing and the 
second longitudinal vein. The results of a chromosome assay carried out on this line confirmed the suspicion that this wing-vein mutation was associated with low chaeta number. The gene was located on the right arm of the second chromosome, near or at a well-known gene of similar phenotype effect, plexus. In common with plexus, the gene behaved as a semi-dominant in crosses between ex $18 \mathrm{~L}$ and unrelated wildtype stocks. Since the gene was not found in either parental inbred line (nor indeed was available in this laboratory) it must have originated as a mutation and we are therefore required to discount the progress made in this sub-line, since our main concern lies with continuous variation.

The absence of any progress in the $25^{\circ} \mathrm{C}$. sub-lines, so long as they were held at $18^{\circ} \mathrm{C}$., is not surprising. We have seen that there is evidence that the $18^{\circ} \mathrm{C}$. environment has limited progress under selection in the main lines, so that progress can hardly be expected in the ex $25 \mathrm{H}$ and ex $25 \mathrm{~L}$ lines so long as they are held at $18^{\circ} \mathrm{C}$. But some progress was to be expected in the ex $18 \mathrm{H}$ sub-line. That this was not obtained could imply that the $18 \mathrm{H}$ line had become homozygous by the thirteenth generation of selection. No back-selection was carried out on either the main or its sub-line so it is not possible to pursue this possibility.

In view of the lack of progress of the sub-lines in their foreign environments it was decided to return them to their respective home environments. This was done after II, I 2 and I 5 generations of selection in the foreign environments for the ex $25 \mathrm{H}$, ex $25 \mathrm{~L}$ and ex $18 \mathrm{H}$ sub-lines respectively. At the same time a further sub-line was set-up from each, in which selection was relaxed and which was held in the foreign environment. The purpose of this was to find out whether any of the sub-lines would regress towards their mid-parent chaeta number value, as this would provide evidence of the stringency of the I $8^{\circ} \mathrm{C}$. environment, for example, with respect to the $25^{\circ} \mathrm{C}$. sub-lines. In fact none of these sub-lines showed any sign of regression after five generations of selection being relaxed and were therefore discontinued.

The behaviour of the sub-lines on being returned to their original home environments, with the exception of ex $25 \mathrm{H}$, merits only the briefest mention. Neither the ex $18 \mathrm{H}$, nor the ex $25 \mathrm{~L}$ lines responded to this change of environment, except that in the former we expected, and in fact observed, a compensatory drop in chaeta number in view of the direct effect of the environment on this character in this line.

In the same way we expect the ex $25 \mathrm{H}$ line to gain about $\mathrm{r} \cdot 7$ chaetæ on being returned to its home environment, but in fact it gained no less than 3.6 chaetx in a single generation. Nor was this the only progress made in this line, for after a slight initial loss in the second generation after transfer, chaeta number increased to an average of 28.5 within five generations of selection. The overall gain was thus 4.6 chaetæ in six generations.

In view of the gain obtained in the first generation after transfer 
to the $25^{\circ} \mathrm{C}$. environment, we must suppose that a considerable amount of genetic variation with respect to chaeta number must have been present in the line at $18^{\circ} \mathrm{C}$., despite the fact that there was no evidence of this so long as the line was held at this temperature. Part of this variation was doubtless present when the sub-line was first established, since, as previously mentioned, the parent line gained two chaetæ immediately after this event. But part also must have been released while the sub-line was held at $18^{\circ} \mathrm{C}$. Since no progress was observed in this environment, this variation could clearly not have been exploitable, so that the immediate effect of the $18^{\circ} \mathrm{G}$. environment on the ex $25 \mathrm{H}$ line must have been actually to reinforce the effect of natural selection in respect of its action on the maintenance of a plateau in response to experimental selection. In short, those genotypes determining high chaeta number were at a distinct disadvantage relative to the fitness of their metrically more mediocre sibs at $18^{\circ} \mathrm{C}$. On transfer to the $25^{\circ} \mathrm{C}$. environment, however, this advantage must have been diminished sufficiently to allow the progress observed. Indeed, the ex ${ }_{25} \mathrm{H}$ sub-line, alone among the four, behaved in the way expected on the correlated response theory.

(c) The chromosome assays

Chromosome assays of the type described by Mather and Harrison (1949) were performed on the four main selection lines and on their respective sub-lines, the purpose of these being to find out whether the environment had caused a differential response to selection between chromosomes and if so, which chromosomes had contributed most to the observed progress of selection.

The first tester stock used was Muller $5 /+; \mathrm{CyL} /+; \mathrm{MeSbe} /+$; which, in prospect, appeared to be a better stock than that used by Mather and Harrison $(\mathrm{ClB} /+; \mathrm{Cyl} / \mathrm{Pm} ; \mathrm{H} / \mathrm{SbIn} 3(\mathrm{R}) \mathrm{Mo})$ because both arms of the third chromosome in this stock carry inversions and because the Muller 5 inversion is viable in male progeny, thus allowing their use in the assay.

Unfortunately, it turned out that the Muller 5 chromosome had so large an increasing effect on chaeta number as to render it quite unsuitable for the present purpose. The tester stock used instead was $\mathrm{ClB} /+; \mathrm{PM} /+; \mathrm{MeSbe} /+$ which offers the first improvement mentioned above, but not the second.

An attempt to carry out the first round of assays was made when the main lines achieved their plateaus, but because of the difficulty just mentioned, the results of these assays were uninterpretable. The next opportunity for assaying the lines then came when their respective sub-lines were returned to their original environments. The main lines, their sub-lines and the inbred lines, Oregon and Samarkand, were all successfully assayed at this time.

The procedure adopted was similar to that described by Mather and Harrison (1949). Females from the tester stock were first crossed 
with males of the line to be assayed. From the progeny of this cross, females whose phenotype was $\mathrm{B} ; \mathrm{Pm} ; \mathrm{MeSb}$ (and hence whose genotype was $\mathrm{ClB} / \mathrm{L} ; \mathrm{Pm} / \mathrm{L} ; \mathrm{MeSbe} / \mathrm{L}$, where $\mathrm{L}$ stands for the appropriate line chromosome) were then backcrossed to line males. Eight phenotypes may be distinguished among the female progeny of this backcross and five individuals from each were scored with respect to their chaeta numbers.

The average chaeta numbers of each of these eight phenotypes is the initial metric of this type of experiment and these, by the adoption

TABLE I

Results of the chromosome assays on the ten lines of the experiment. The entries in the table are the average line chromosome excesses over the tester chromosomes. Significant excesses are indicated by asterisks (residual mean square $=0.43$ for 119 degrees of freedom; see table 2).

\begin{tabular}{|c|c|c|c|c|c|c|c|c|}
\hline \multirow{2}{*}{ Line } & \multirow{2}{*}{$\begin{array}{l}\text { No. of } \\
\text { Assays }\end{array}$} & \multicolumn{3}{|c|}{ Main effects } & \multicolumn{4}{|c|}{ Interactions } \\
\hline & & I & II & III & I/II & I/III & II /III & $\mathrm{I} / \mathrm{II} / \mathrm{III}$ \\
\hline 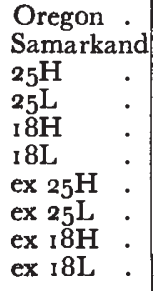 & $\begin{array}{l}6 \\
5 \\
2 \\
2 \\
2 \\
2 \\
2 \\
2 \\
2 \\
2\end{array}$ & $\begin{array}{c}-0.08 \\
0.58 \\
1.14^{*} \\
-1.00^{*} \\
0.33 \\
-1.19^{*} \\
1.81 * * * \\
-0.77 \\
0.87 \\
-0.77\end{array}$ & $\begin{array}{l}1 \cdot 71^{* * *} \\
0 \cdot 69^{*} \\
2 \cdot 04^{* * *} \\
1 \cdot 10^{*} \\
1 \cdot 71^{* * *} \\
0 \cdot 47 \\
1 \cdot 36^{* *} \\
0.87 \\
1 \cdot 19^{*} \\
-0.31\end{array}$ & $\begin{array}{c}0.12 \\
0.02 \\
1.21 * * \\
-0.60 \\
0.88 \\
-0.89 \\
1 \cdot 36^{* *} \\
-0.29 \\
0.52 \\
-0.47\end{array}$ & $\begin{array}{l}-0.20 \\
-0.54 \\
1.62 * * * \\
-0.15 \\
-0.48 \\
0.37 \\
-0.43 \\
0.52 \\
-0.37 \\
-0.51\end{array}$ & $\begin{array}{r}0.13 \\
0.30 \\
-0.56 \\
-0.15 \\
-0.26 \\
-0.34 \\
-0.08 \\
-0.79 \\
0.17 \\
0.34\end{array}$ & $\begin{array}{c}0.10 \\
0.24 \\
0.14 \\
-0.05 \\
0.4^{8} \\
0.22 \\
1.18^{*} \\
0.09 \\
0.19 \\
0.04\end{array}$ & $\begin{array}{l}-0.11 \\
-0.61 * \\
-0.59 \\
-0.40 \\
-0.20 \\
-0.54 \\
-0.11 \\
-0.17 \\
0.34 \\
-0.41\end{array}$ \\
\hline Average & 27 & 0.12 & $I \cdot 13$ & $0 \cdot 16$ & $-0 \cdot I I$ & -0.04 & 0.23 & -0.29 \\
\hline
\end{tabular}

$* \mathrm{P}=0 \cdot 05-0 \cdot 01$

** $\mathrm{P}=0.01-0.001$

*** $\mathrm{P}<0.001$

of appropriate orthogonal comparisons, can be made to yield information about the excess chaeta-producing capacities of the line chromosomes, both individually and in combination, relative to their tester homologues. The results of the assays obtained in this way are shown in table $I$ and fig. 3 .

As it was not convenient to assay all ten lines on the same occasion, the programme was carried out in three rounds, in each of which duplicate cultures of Oregon and Samarkand were included. Each selection line was also assayed in duplicate and all assays were done at $25^{\circ} \mathrm{C}$.

The inclusion of Oregon and Samarkand in each round of the assay provides our estimate of error variance against which differences between selection lines may be assessed, for the former, although not necessarily the latter, are not likely to be segregating with respect to differences concerning chaeta number. Preliminary analysis of the 
assay results showed, however, that the pooled within line variance $(N=9)$ obtained from the inbred lines was not significantly smaller than that obtained from the selection lines $(N=8)$. They were accordingly pooled with the latter to provide seven separate within line variances-one for each orthogonal comparison available among the eight phenotypes found in the backcross cultures-each with I 7 degrees of freedom. Furthermore, since these seven within line variances were only just heterogeneous $\left(\chi_{(6)}^{2}=13.557 ; P=0.05-\right.$ $0 \cdot 02$ ), they were in turn pooled to yield an overall estimate of error variance with I 9 degrees of freedom.

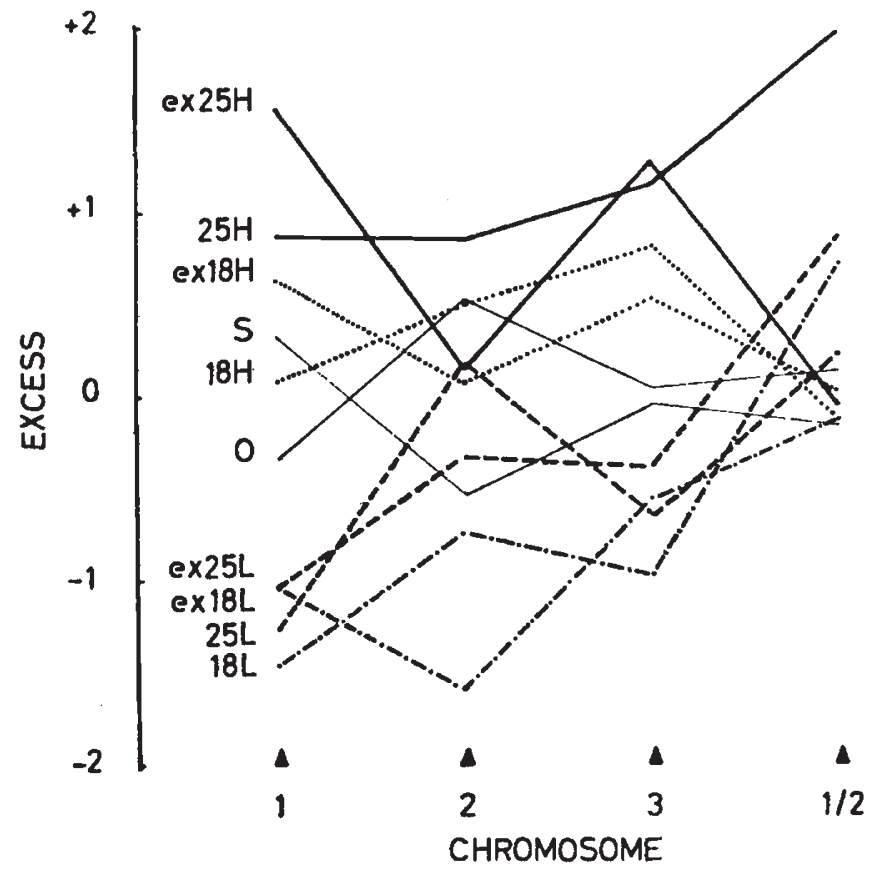

FIG. 3.-Results of the chromosome assays. The excesses relate to mid-parent performance and not that of the tester stock as in the case of tables I, 2 and 3 .

The rest of the analysis of variance, that concerned with variation between lines, falls into two parts. The first part is concerned with the variation between the ten lines assayed (the lines item with 9 degrees of freedom) while the second part concerns the average difference between the line, on the one hand, and the tester stock chromosomes on the other (the deviation item with a single degree of freedom). There is both a lines and a deviation item for each one of the seven analyses concerned with the seven orthogonal comparisons between line and tester chromosomes.

Turning now to these analyses (table 2), we find that in only two of the seven is the deviation item significant, namely, II and I/II/III. Since the lines item of the latter analysis is not significant, it is clear that this complex interaction contributes nothing to variation between 
lines and must therefore be peculiar to the tester stock. For this reason it is of no further interest. On the other hand, since the lines item of II is significant we have clear evidence that variation in respect of chactaproducing capacity is present both between lines and betwcen these and the tester stock. Reference to table I shows that only the second chromosome of the ex $18 \mathrm{~L}$ sub-line (the line with the plexus-like mutation) has a lower, though non-significant, capacity than that of the tester stock. To put it another way, the chaeta producing capacity of the second chromosome of the tester stock is low relative to that of the average line chromosome; hence the significance of the deviation

TABI.E 2(a)

(a) Analysis of variance of chromosome assays. Entries are mean squares

\begin{tabular}{|c|c|c|c|c|c|c|c|c|}
\hline Item & $\mathrm{N}$ & I & II & III & $\mathrm{I} / \mathrm{II}$ & $1 / I I I$ & $\mathrm{II} / \mathrm{III}$ & $\mathrm{I} / \mathrm{II} / \mathrm{III}$ \\
\hline $\begin{array}{l}\text { Deviation } \\
\text { Lines }\end{array}$ & $\begin{array}{l}\text { I } \\
9\end{array}$ & $\begin{array}{l}0 \cdot 3^{8} \\
2 \cdot 15^{* * *}\end{array}$ & $\begin{array}{c}34 \cdot 45^{* * *} \\
1 \cdot 18^{* * *}\end{array}$ & $\begin{array}{l}0.67 \\
1 \cdot 22 * *\end{array}$ & $\begin{array}{l}0.28 \\
1 \cdot 01\end{array}$ & $\begin{array}{l}0.04 \\
0.34\end{array}$ & $\begin{array}{l}I \cdot 51 \\
0.26\end{array}$ & $\begin{array}{l}2 \cdot 28^{*} \\
0.22\end{array}$ \\
\hline Residual & 119 & \multicolumn{7}{|c|}{0.43} \\
\hline
\end{tabular}

TABLE $2(b)$

The break-down of the Lines SS of $(a)$. (See text)

\begin{tabular}{|c|c|c|c|c|c|}
\hline Item & $\mathrm{N}$ & I & II & III & $\mathrm{I} / \mathrm{II}$ \\
\hline $\begin{array}{l}\text { Between groups. } \\
\text { Within groups }\end{array}$ & $\begin{array}{l}2 \\
7\end{array}$ & $\begin{array}{l}7 \cdot 80^{* * *} \\
0.53\end{array}$ & $\begin{array}{l}2 \cdot 30^{* *} \\
0.86\end{array}$ & $\begin{array}{l}4.93^{* * *} \\
0.17\end{array}$ & $\begin{array}{l}0.59 \\
1 \cdot 13^{*}\end{array}$ \\
\hline
\end{tabular}

item of this analysis. In the remaining five analyses, the chromosomes of the tester stock do not appear to differ much from the average effect of those of the lines.

The chromosomes of the lines, on the other hand, vary considerably among themselves, both with respect to the chaeta-producing capacity of all three chromosomes as well as with respect to that concerning an interaction between the first and the second. Selection has clearly changed the genic content of all three chromosomes and indeed it would have been surprising if it had not acted in this way. Of greater interest, however, is the possibility that selection has caused a given response to have been achieved in different ways, with respect to the chaeta producing capacities of the chromosomes, in different environments. Reference to fig. 3 suggests that it has not, for most of the variation between lines concerns the difference between the high, the low and the parental inbred lines. Grouping the lines in this way, we 
may proceed to partition the 9 degrees of freedom of the lines item of the I, II, III and I/II analyses into a between groups and a within groups item with 2 and 7 degrees of freedom respectively. This partition is shown in the lower half of table 2. The between groups item clearly accommodates most of the variation between lines in the case of the I, II and III analyses, but fails to do so in the case of the I/II analysis. With the exception of the latter comparison therefore, the sole effect that the $18^{\circ} \mathrm{C}$. environment has had on the response to selection has been to limit it, there being no evidence that the environment has determined a differential response by the chromosomes to selection.

Now we have seen that the ex $18 \mathrm{H}$ and the ex ${ }_{25} \mathrm{~L}$ sub-lines failed to make any progress under selection, so we expect good agreement between the assays of these and those of their respective main linesan expectation which is in fact realised. The results of the ex $18 \mathrm{~L}$ assay, on the other hand, show quite clearly the effect of the plexus-like mutation on its second chromosome and that the observed progress of this line was due almost entirely to a change on this chromosome only.

The comparison of the $25 \mathrm{H}$ and the ex ${ }_{25} \mathrm{H}$ assays, however, is less straightforward. While the sub-line appears to have gained some increasing genes on its first chromosome and to have lost an equivalent amount of activity on its second chromosome, the most remarkable feature of this comparison concerns the interaction between chromosomes I and II. The assays show quite clearly that it is the $25 \mathrm{H}$ line which has profited from this interaction and it is therefore the comparison between this and the other lines which has caused the significance of the within groups item in the partition of the lines of the I/II analysis (table 2). Yet, surprisingly, the ex ${ }_{25} \mathrm{H}$ sub-line appears to have lost this advantageous interaction, although profiting from an interaction concerning chromosomes II and III (table I). Furthermore, this assay comparison is not in accord with observations on the two lines concerned, for it is reasonable to suppose that where an interaction between the sex-chromosome and an autosome has made a considerable contribution to progress under selection, the average chaeta numbers of the sexes should differ by more than they customarily do. Yet it was the females of the ex $25 \mathrm{H}$ line which averaged I 8 chaetæ more than their male sibs (at $25^{\circ} \mathrm{C}$.), the sex difference of the $25 \mathrm{H}$ line being no more than is usuaal. We can only conclude that the assays of these lines have failed to detect all the differences between them. Why should this be so?

Now the assays will recover only a part of the total difference in chaeta number between the lines on the one hand and the tester stock on the other. That part which is recovered for any particular line may be gained by summing over those comparisons whose excesses, relative to the tester stock are significant (see table $\mathbf{I}$ ).

The assessment of the observed difference between line and tester 
stock chaeta numbers, however, poses a difficulty, since the chromosomes of the latter carry recessive lethals. Tester homozygotes therefore do not exist. But by taking the average chaeta numbers of $\mathrm{ClB} / \mathrm{L}$; $\mathrm{Pm} / \mathrm{L} ; \mathrm{MeSbe} / \mathrm{L}$ females, which are found in every culture of the assay experiment, we may obtain an approximation to the unknown chaeta number of the tester homozygote. Each observed difference between line and tester heterozygote can then be compared with that recovered by assay in the form of an efficiency percentage and these are shown in table 3 .

Before turning to these, however, we need to consider what factors might be expected to affect efficiencies in general. Now in view of the

TABLE 3

The efficiencies of the line assays. The fourth column is gained by summing the significant excesses shown in table I

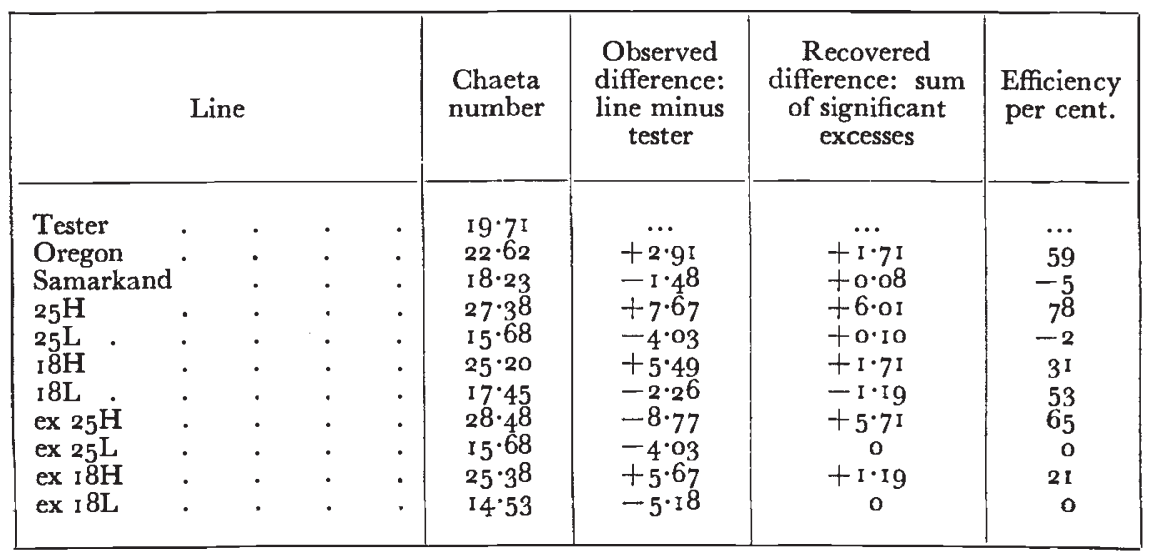

approximation resorted to above, it is clear that only if all the tester genes (at least, those determining chaeta number) are completely dominant to their line allelomorphs, will this approximation be perfect. The assay efficiency here would be Ioo per cent. To put it another way, if all the genes in a line are dominant to their tester allelomorphs, then apart from sampling variation, the chacta number of line homozygotes will be identical to that of the tester heterozygote. Assay efficiency in this case will be zero. We may therefore expect the line assays to vary with respect to their efficiencies according as the dominance relations between line and tester allelomorphs varies.

Although not of the same importance as that concerned with dominance relations, two further factors can also be expected to affect the efficiency of assays. The first of these concerns the degree to which the marked inversions of the tester stock prevent effective crossing-over between line and tester chromosomes. No attempt has been made in this experiment to estimate losses from this cause, but Mather and Harrison (I 949) showed that this amounted to only Io per cent. of the H 2 
original difference between line and tester stock. In any case, all assays can be expected to be on average affected equally in this respect.

The second point concerns the magnitude of the observed difference between line and tester stock. Where this is small, the recovered difference will also be small and the sampling variance of the latter may be expected to be occasionally large enough to reverse the sign of the recovered difference. When this happens, the efficiency percentage will be negative, which is of course an absurdity.

Turning now to the efficiencies obtained in the present experiment (table 3), we notice two negative values, those of the Samarkand and the ${ }_{25} \mathrm{~L}$ assays. The observed difference between Samarkand and the tester stock chaeta number is the smallest of all the differences shown in the table, so that we need have little hesitation in ascribing this negative value to sampling variation. However, though the comparable difference for the ${ }_{25} \mathrm{~L}$ line is larger, there is no way of accounting for its negative value other than due to the same cause. This conclusion receives some support when we notice that the appropriate excesses in the case of both Samarkand and ${ }_{25} \mathrm{~L}$ are only just significant. It is probable, therefore, that the " true" value for both assays is zero.

The variation between the values of the other assays is considerable and if taken at their face value suggest that selection has caused some change with regard to the dominance relations of genes determining chaeta number. In the first place, a comparison of the efficiency values of the main lines with those of their respective sub-lines confirms our observations on the progress of selection in the latter. Thus, making some allowance for sampling variation, the efficiencies of the ex $25 \mathrm{H}$, ex ${ }_{25} \mathrm{~L}$ and ex $18 \mathrm{H}$ sub-lines are similar to those of their parent lines. In so far that selection in the latter two sub-lines resulted in no response, this is to be expected. A considerable response was, of course, obtained in the ex $25 \mathrm{H}$ sub-line, but this appears to have caused little, if any, change in the dominance properties manifested by the parent line.

The considerable difference between the value of the ex I8L assay and that of its parent line, I8L, calls for comment, for selection in the foreign environment appears to have very strongly favoured dominant genes. The assessment of dominance relationships here, however, must be treated with some caution, for as is common in quantitative genetics, they are weighted estimates of the average dominance of all contributing genes. Now we have seen that the progress of the ex I $8 \mathrm{~L}$ line was achieved as the result of a major mutation on the second chromosome, so that we might expect this gene to exert a disproportionate effect with regard to dominance. Furthermore, it will be recalled, that this plexus-like mutant behaved as a semi-dominant in crosses between the line and wild-type stocks, at least, with respect to wing venation. Though its dominance relations with respect to chaeta number are not known, it is not unreasonable to suppose that 
this might be similar to those concerning its effect on wing variation, since both hairs and veins are composed of the same material, namely, chitin.

Having gone some way to establish that assay efficiencies can be used, with qualification, to interpret the effects of selection on dominance, it is tempting to go further and ask what they tell us about selection in the main lines. Now the efficiencies of the $25 \mathrm{H}$ and $25 \mathrm{~L}$ lines are 78 per cent. and -2 per cent. (read o per cent.) respectively. This suggests that the effect of selection for high chaeta number at $25^{\circ} \mathrm{C}$. has been to favour recessive genes, whilst selection for low number has favoured their dominant allelomorphs. Whenever selection acts in this way, we expect to obtain a greater response in the direction opposite to that of dominance, which, in this case, indicated the upward direction. And, as we have seen, the direction of asymmetry at $25^{\circ} \mathrm{C}$. did in fact favour the high line.

Now the direction of asymmetry at $18^{\circ} \mathrm{C}$. was opposite to that at $25^{\circ} \mathrm{C}$. If the dominance hypothesis is to provide an adequate explanation of asymmetry of response in this environment too, then clearly, we expect to find that recessive genes have been favoured in the $18 \mathrm{~L}$ line and their dominant allelomorphs in the $18 \mathrm{H}$ line. The assay efficiencies, at 53 per cent. and $3^{1}$ per cent. respectively, of these lines appear to support this expectation, although strictly, an assay efficiency at or around $5^{\circ}$ per cent. indicates a preponderance of neither dominant nor recessive allelomorphs, but a balance of them both. Unfortunately, we must now recall that all assays were carried out in one and the same environment, $25^{\circ} \mathrm{C}$. Thus the information which we have about dominance relationships of the $18 \mathrm{H}$ and $18 \mathrm{~L}$ lines relates to their performance at $25^{\circ} \mathrm{C}$., and not to the environment in which selection was practised. This drawback would be of no consequence if it could be shown that the direction of asymmetry shown by the lines at $18^{\circ} \mathrm{G}$. was not susceptible to alteration by a change of the environment. But as we have already seen, this is not the case, as reference to fig. 2 shows. The departures of the $25 \mathrm{H}$ and $25 \mathrm{~L}$ lines from their mid-parent, at the first generation after that at which their sub-lines were established, amount to +5.4 and -4.8 chaetæ respectively. The chaeta number of their sub-lines, ex ${ }_{25} \mathrm{H}$ and ex ${ }_{25} \mathrm{~L}$, at the same generation, depart from the $18^{\circ} \mathrm{C}$. mid-parent, by $+2 \cdot 1$ and -5.7 chaetæ respectively. There is no doubt that the direction of asymmetry here is in fact susceptible to change by the environment and the same is true with respect to the asymmetry of the $18 \mathrm{H}$ and $18 \mathrm{~L}$ lines. The effect of the environment on the direction of asymmetry of response to selection is summarised in fig. 4 .

In summary then, it seems that the asymmetry of response to selection obtained in the $25^{\circ} \mathrm{C}$. environment is very likely due to the selection of dominant genes in the low line and recessive genes in the high line. The assays of the $18 \mathrm{H}$ and $\mathrm{r} 8 \mathrm{~L}$ lines, however, provide no comparable information. What we need here is to know the efficiency 


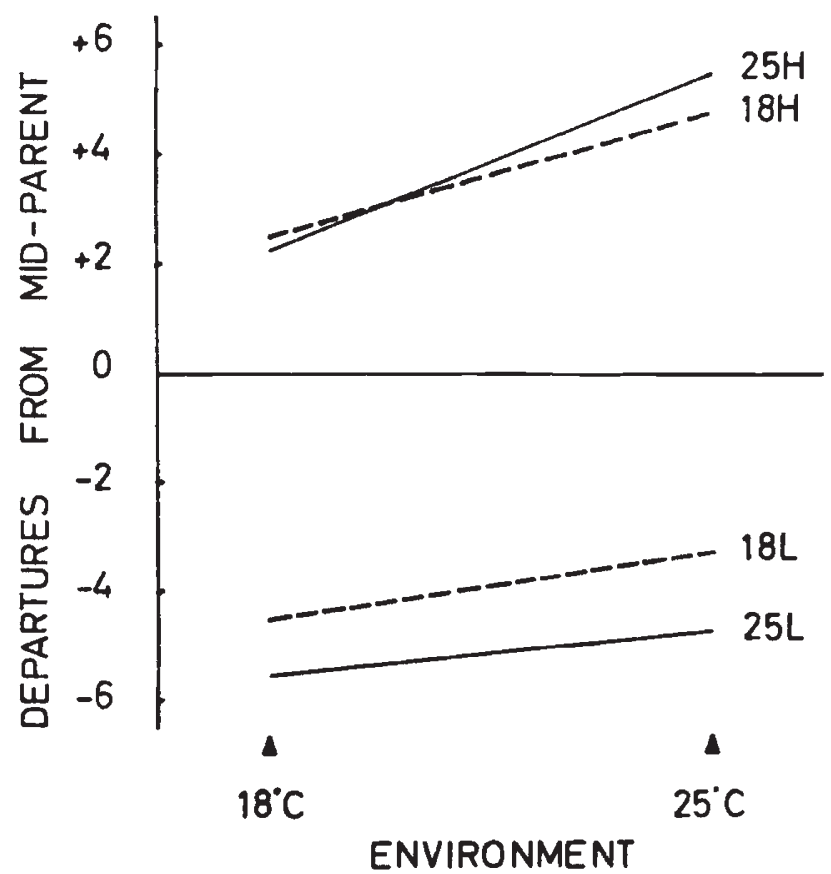

Fig. 4.-Effect of the environment on asymmetry of response to selection.

of the assays of all four main selection lines when they are assayed at $18^{\circ} \mathrm{C}$. Unfortunately, this information is not available and this problem clearly requires more evidence before we are able to offer its solution.

\section{DISCUSSION}

We now have to consider three points on which discussion has been deferred from earlier sections of this paper. The first of these concerns the effects of the environment on the supply and availability of genetic variance.

We have seen that the response to selection obtained in the $18^{\circ} \mathrm{C}$. environment was less than that obtained at $25^{\circ} \mathrm{C}$. In view of the evidence indicating that the frequency of recombination is, on average, higher at $18^{\circ} \mathrm{C}$. than at $25^{\circ} \mathrm{C}$., it has been argued that the environment not only determines the supply of genetic variation, but its availability also. The availability of genetic variation will always depend, of course, on the fitness of the genotypes favoured by selection. If their fitness is markedly inferior to that of their more mediocre sibs, then the response to selection will be correspondingly diminished, if not actually halted.

The effects of the environment in those two respects ought to be capable of experimental separation, since they are concerned with different stages of the life cycle. Thus the stage at which the environment controls the supply of genetic variation is, of course, the meiosis 
of the parents of any given generation. The effect of the environment on fitness, on the other hand, concerns the zygotes which are the result of fusion of the products of that meiosis.

An attempt was therefore made to separate and estimate the effects of the environment on genetic variation. The progenies of flies reared at $18^{\circ} \mathrm{C}$. were raised and scored at both $18^{\circ} \mathrm{C}$. and $25^{\circ} \mathrm{C}$. On the above argument, we expect the genetic variance of the latter to exceed that of the former. At the same time, the progenies of flies reared at $25^{\circ} \mathrm{C}$. were raised and scored at $18^{\circ} \mathrm{C}$. and $25^{\circ} \mathrm{C}$., with a view to obtaining a factorial design of the treatments. The experiment was therefore concerned with the four environmental treatments, I8/18, 18/25, 25/18 and 25/25-the figures before the oblique stroke referring to the temperature of the parental and that after, to that of the filial environment.

Cultures of Oregon and Samarkand, together with their $F_{1}, F_{2}$ backcross progenies were subjected to each of these treatments, but in view of the lack of success of this experiment with respect to its intended purpose, it is not worthwhile mentioning the procedure and analyses adopted. The size of the experiment was admittedly the minimum needed to yield the information required and there was evidence that its size could have been profitably increased. It is hoped therefore that a future attempt at this type of experiment will prove to be more successful.

The second point concerns the relationship between chaeta number and temperature. The usual effect of lower temperature on chaetæ is to increase their number, that is, the correlation between number and temperature is negative. But by the time that the high selection lines in both environments had reached a plateau in response to selection, this correlation had apparently become positive.

The nature of the usual, negative correlation of chaeta number with temperature has been investigated by Beardmore and discussed by Thoday (1958). They observed that the effect of natural selection on the average chaeta numbers of populations started from a cross between Oregon and Samarkand enhanced the direct or developmental effect of temperature on this character. Thoday therefore argued that the developmental change of number with change of temperature must be adaptive.

So long as our observations are confined to inbred lines and we are concerned with changes of temperature which are not so great as to cause pronounced changes in viability, the effect of the temperature of the environment can only be by adding or subtracting a constant increment of chaetæ to all the individuals within a culture. In this case, the mean of the distribution of chaeta numbers would change, but without its variance necessarily changing at the same time. In graphic terms, the distribution would appear to move backwards or forwards along the abscissa without any accompanying change in its shape. 
If we look at the distributions of the main selection lines concerned ( $18 \mathrm{H}$ and $25 \mathrm{H}$ ) and compare them with those of their respective sub-lines (ex $18 \mathrm{H}$ and $\mathrm{ex}{ }_{25} \mathrm{H}$ ), there is no evidence that this is what is happening (fig. 5). In both comparisons, the distribution of the sub-line is contained by that of its main line, even though the mean of the latter is clearly different from the former. Furthermore, although these distributions are based on a small number of observations (40 males and 40 females), there is some indication that the shapes of the distributions have changed as well.

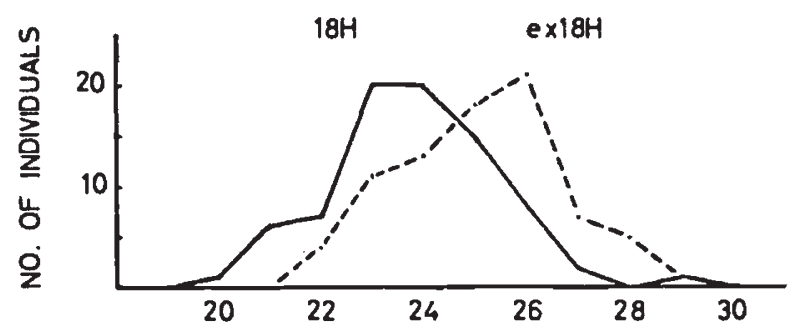

CHAETA NUMBER

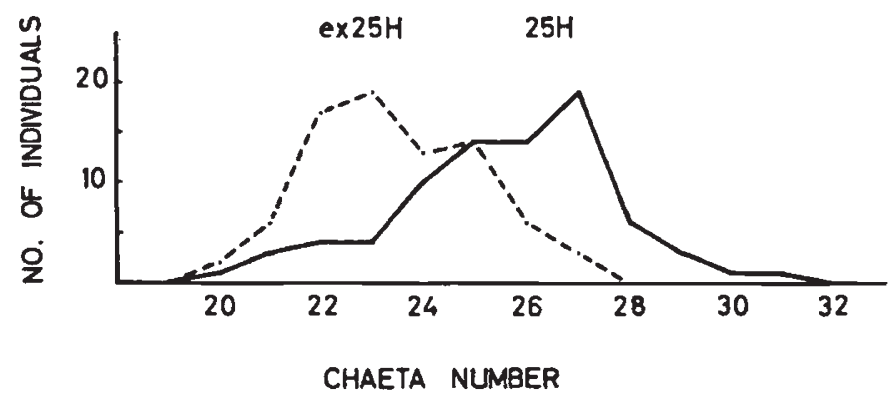

FiG. 5.-Distributions of chaeta numbers of the high selection lines in their home and foreign environments. Each distribution concerns the counts obtained from 40 male and 40 female flies.

Now in the present circumstances we are not confining our observations to inbred lines, for one line at least, ${ }_{25} \mathrm{H}$, as well as its sub-line, ex ${ }_{25} \mathrm{H}$, clearly made further progress under selection. In this case, the environment could modify the effect of natural selection such that different genotypes, determining different chaeta numbers, were favoured in different environments. We should thus expect both the mean and the variance of the distribution of chaeta numbers to change. The comparison between the distributions of the $25 \mathrm{H}$ and ex $25 \mathrm{H}$ lines suggests that those genotypes determining chaeta numbers of 28 or more at $25^{\circ} \mathrm{C}$., fail to survive at $18^{\circ} \mathrm{C}$. and this interpretation is, of course, consistent with the results discussed earlier. High chaeta numbers also appear to be favoured in the $18^{\circ} \mathrm{C}$. selection lines when these are raised at $25^{\circ} \mathrm{C}$. Since, however, neither the main, nor its sub-line responded to selection after the time at which the latter were 
started, we have no evidence that these lines were segregating. It is therefore difficult to see how their chaeta numbers could respond to a change of temperature in any other but a developmental way-despite the lack of graphical support for this suggestion. These results certainly suggest that further investigation of the genetic determination of the developmental response of chaeta number to the temperature of the environment would be profitable.

The third point of interest raised by a consideration of the results of this experiment concerns the causation of plateaus in response to selection. So far, the correlated response theory has been discussed to the exclusion of others, principally, the expressivity theory. We must now ask whether the results of this experiment can be more easily interpreted by the expressivity theory.

Now, as we have seen, only one line, ex $25 \mathrm{H}$, behaved in a useful way. Even in this, the new genetic variance produced by exposure to a foreign environment, could be exploited only by returning the line to its original environment. On the expressivity theory it can be argued that the effect of the foreign environment was to promote the expression of hitherto unexpressed genes. But if this was true, why was the emergence of this new variation not accompanied by an immediate response to selection? It could, of course, be further argued that this variation was not immediately available to selection for the same reason as that advanced earlier on the correlated response view, namely, that otherwise desirable genotypes are relatively unfit. But this argument poses a difficulty, for we are required to suppose that the expression of these desirable genotypes persist in the $25^{\circ} \mathrm{C}$. environment, despite the absence of those very environmental conditions needed to secure their expression. In short, there is little doubt that the results of the present experiment are better explained on the correlated response theory.

\section{SUMMARY}

This paper is concerned with an investigation of the effect of varying the environment on the disruption of plateaus in response to selection. Selection for high and low sternopleural chaeta number, begun in each of two environments, $18^{\circ} \mathrm{C}$. and $25^{\circ} \mathrm{C}$., from the progeny of a cross between the inbred lines of Drosophila melanogaster, Oregon and Samarkand, was continued until each selection line had reached a plateau in response to selection.

A sub-line was established from each main line and transferred to the foreign environment, selection being continued as before. Only one sub-line, that of the low line from the $18^{\circ} \mathrm{C}$. environment made any progress under selection, achieved, however, as the result of a major mutation on the second chromosome.

The sub-lines were then transferred to the environments of their respective main lines, where one, that of the high line from the $25^{\circ} \mathrm{C}$. environment, made an immediate response to selection. Since this 
line made no progress in its foreign environment, it has been suggested that the $18^{\circ} \mathrm{C}$. environment had had a dual effect on genetic variance; by increasing the average frequency of recombination, the supply of genetic variance had been increased, but because the desirable recombinant genotypes were unfit relative to their metrically more mediocre sibs, the availability of genetic variance had been restricted.

Chromosome assays carried out on the main and sub-lines showed that selection had changed the genic complements of the three major chromosomes and that one line had profited from an interaction between the first and second. There was no evidence that response to selection had been achieved in different ways in different environments. But the assays suggest that selection had had a differential effect with respect to dominance and that this had accounted for the asymmetry of response in the $25^{\circ} \mathrm{C}$. environment.

Lastly, three points are considered; the experimental partitioning of the environmental effect on the supply and availability of genetic variance; the nature of the positive correlation between chaeta number and temperature shown by the high selection lines; and the theory of the causation of plateaus in response to selection.

Acknowledgments.-I am indebted to Prof. K. Mather, D.sG., F.R.s., and to Dr J. L. Jinks for advice and criticism throughout the course of this work.

\section{REFERENCES}

BREESE, E. L., AND MATHER, K. 1957. The organisation of polygenic activity within a chromosome in Drosophila. I. Hair characters. Heredity, II, 373-395.

BREESE, E. L., AND MATHER, K. I96o. The organisation of polygenic activity within a chromosome in Drosophila. II. Viability. Heredity, 14, 375-399.

GLAYTON, G. A., AND ROBERTSON, A. 1957. An experimental check on quantitative genetical theory. II. The long-term effects of selection. 7. Genet., 55, I52-I 70 . GIBSON, J. B., PARSONS, P. A., AND SPICKETT, S. G. I96r. Correlations between chaeta number and fly size in Drosophila melanogaster. Heredity, $16,349-354$.

LAWRENCE, M. J. 1958. Genotypic control of crossing-over on the first chromosome of Drosophila melanogaster. Nature, I 82, 889-89o.

LAWREnce, M. J. 1963. The control of crossing-over in the X-chromosome of Drosophila melanogaster. Heredity, $181,27-46$.

LERNER, I. M. I958. The genetic basis of selection. John Wiley, New York.

MATHER, K. I94I. Variation and selection of polygenic characters. 7. Genet., $4^{I}$, I59-193.

MATHER, K., AND harRison, B. J. I949. The manifold effect of selection. Heredity, $3, \mathrm{I}-52, \mathrm{I} 3 \mathrm{I}-\mathrm{I} 62$.

plovgr, H. H. I917. The effect of temperature on crossing-over in Drosophila. 7. Exp. Zool., 24, 147-209.

PLUNKETT, G. R. 1926. The interaction of genetic and environmental factors in development. F. Exp. Zool., 46, 181-245.

RASMUSON, M. 1955. Selection for bristle number in some unrelated strains of Drosophila melanogaster. Acta. Zool. Stockholm, 36 , I-49.

robertson, A. 1955. Selection in animals : synthesis. Cold Spr. Harb. Symp. quant. Biol., 20, 225-229.

THODAY, J. M. I958. Homeostasis in a selection experiment. Heredity, 12, 40I-415. 